\title{
Xp22.13p22.2 duplication syndrome
}

INSERM

\section{Source}

INSERM. (1999). Orphanet: an online rare disease and orphan drug data base.

Xp22.13p22.2 duplication syndrome. ORPHA:284180

Xp22.13p22.2 duplication syndrome is a rare syndromic intellectual disability

characterized by developmental delay and intellectual disability, learning and behavioral problems, short stature, thin and sparse hair, mild dysmorphic features, tapering fingers

and later onset of scoliosis, obesity and cardiovascular problems (cardiomeg aly and cardiomyopathy). Females have normal intelligence. 